\title{
УСТОЙЧИВОЕ РАЗВИТИЕ В ОСУЩЕСТВЛЕНИИ СОЦИАЛЬНО- ЭКОНОМИЧЕСКОЙ РЕГИОНАЛЬНОЙ ПОЛИТИКИ: ВОПРОСЫ ПРИВЛЕЧЕНИЯ БИЗНЕСА К СОЦИАЛЬНО ОРИЕНТИРОВАННЫМ И ЭКОЛОГИЧЕСКИМ ИНИЦИАТИВАМ
}

\author{
(c) 2020 Полуянова Наталья Владимировна \\ кандидат экономических наук, старший научный сотрудник, международная научно- \\ исследовательская лаборатория пространственной экономики \\ Белгородский государственный национальный исследовательский университет, Россия, Белгород \\ E-mail nvp-nir@yandex.ru
}

В статье исследуется необходимость ориентации социально-экономической региональной политики на общепринятые цели устойчивого развития. Продемонстрированы соответствующие инициативы и сложившийся зарубежный опыт участия бизнеса в решении экологических и социальных проблем общества. Сделаны выводы относительно развития ситуации в России в рамках общемировых тенденций. Также автор приходит к заключению о необходимости формирования в обществе ценностного этического императива, согласно которому потребители должны выбирать социально ответственные компании, поскольку именно общественный запрос со стороны общества в регионах, наряду с административной поддержкой будут создавать условия для бизнеса, благодаря которым они станут активно выступать соинвесторами осуществления целей устойчивого развития в рамках проведения социально-экономической региональной политики.

Ключевые слова: устойчивое развитие, экологический эффект, социальный эффект, бизнес, софинансирование, регион, социально-экономическая региональная политика, моральный императив

\section{Введение}

В реализации социально-экономической региональной политики применительно к регионам России необходимо опираться на проявляющиеся тенденции в эволюционировании социума и экономики, что предполагает исследование общих закономерностей в целевых установках относительно развития регионов в глобальном масштабе в рамках общемировых трендов.

В отмеченном глобальном масштабе очевидной стала тенденция, связанная с ориентирами общества на цели долгосрочного устойчивого развития, которые предполагают, помимо экономического эффекта при осуществлении социально-экономических преобразований, учет экологических и социальных факторов и соизмерение предпринимаемых действий с достижением желательных результатов по этим трем направлениям. Это тренд нашел отражение в поиске эффективной модели функционирования социума, переходе от так называемой «коричневой» модели развития к ее «зеленому» варианту [1, 3].

Подчеркивая значимость таких целевых установок для регионов России, можно отметить, что еще в 2017 г. премьер-министром РФ было дано поручение по разработке детального плана перехода на модель экологически устойчивого развития, согласно которому необходимо было разработать и внедрить: «систему индикаторов устойчивого развития, определение механизма достижения целей и поэтапное решение задач экологически устойчивого развития территорий регионов на период до 2030 года и на перспективу до 2050 года» [5].

Выше изложенное актуализирует исследование вопросов нацеленности общества на устойчивое развитие, участия в этом процессе бизнеса в регионах и основных факторов устойчивого регионального развития в рамках осуществления социально-экономической региональной политики.

\section{Материалы и методы}

В исследовании вопроса ориентации регионов России на проявившиеся в глобальном масштабе цели устойчивого развития общества, ознаменовавшего переход от «коричневой» модели экономики к «зеленой», в фарватере возможностей осуществления социально-экономической региональной политики за счет вовлечения бизнеса в участие в социально значимых и экологических инициативах, нами проведен литературный обзор установок устойчивого развития, 
понимания его основных эффектов, участия и места регионов России в национальном экологическом рейтинге. Также исследованы основные факторы устойчивого развития региона и зарубежный опыт вовлеченности бизнеса в цели устойчивого развития. Использованы следующие общенаучные методы: описания, обобщения, сравнительного анализа и синтеза полученной информации.

\section{Обсуждение}

Экспертным сообществом при характеристике нацеленности на устойчивое развитие делается акцент на направленной на три основных направления развития модели: экономическое, экологическое и социальное. При этом, участие данных составляющих в обществом развитии не рассматривается в качестве паритетного, поскольку приоритет отдается экологическому и социальному эффектам, а экономический является желанным, но вторичным в этом сочетании [3].

Исследователи полагают, что именно такая расстановка приоритетов позволит социуму бесконфликтно функционировать и дать человечеству «шансы на будущее», поскольку иной вариант хозяйствования обрекает его на исчерпание возможностей существования [4].

Ряд ученых полагают, что успешность в реализации устойчивого развития зависит от нахождения правильного сочетания социального, экологического и экономического эффектов [8].

Применительно к региональному аспекту устойчивого развития, исследователями справедливо отмечается, что его также нельзя отождествлять с достижением только ряда экономических показателей [9]. Соответственно, при исследовании устойчивости региона оценивают его резистентность к внешним воздействиям и возможности функционирования в существующем окружении при обеспечении необходимого уровня качества жизни членов регионального социума, что также акцентирует внимание на социальных и экологических факторах, помимо экономических [2, 12].

Представленный подход в полной мере сочетается с программными документами ООН в части нацеленности на сохранение окружающей среды, в рамках которых говориться, что новая модель экономического развития определяет необходимость: «повышения благосостояния людей и обеспечение социальной справедливости... снижение рисков для окружающей среды и обеднения природы» [6].

Представленные точки зрения определяют необходимость исследования актуальных составляющих обеспечения устойчивого развития регионов России и выявление роли и вовлеченности бизнеса в этот процесс с учетом сложившейся общемировой практики.

\section{Результаты}

Можно отметить, что сегодня регионы России уже вовлечены в мониторинг экологических параметров, характеризующих нацеленность властей и социума на устойчивое развитие. Так, ежегодно анализируются и публикуются результаты национального экологического рейтинга регионов, лидерами которого в 2019 г. являются следующие 10 субъектов (таблица 1).

Наряду с регионами - лидерами в данном рейтинге, есть регионы - аутсайдеры (таблица 2).

Таблица 1. Регионы России, занимающие лидирующие позиции в национальном экологическом рейтинге [10]

\begin{tabular}{|c|c|c|c|c|c|}
\hline № & Регион РФ & $\begin{array}{c}\text { Природо- } \\
\text { охранный } \\
\text { нндекс }\end{array}$ & $\begin{array}{c}\text { Промышленно- } \\
\text { экологический } \\
\text { нндекс }\end{array}$ & $\begin{array}{c}\text { Социально- } \\
\text { экологический } \\
\text { нндекс }\end{array}$ & $\begin{array}{c}\text { Сводный } \\
\text { экологический } \\
\text { нндекс }\end{array}$ \\
\hline $\mathbf{1}$ & Тамбовская область & $72 / 28$ & $60 / 40$ & $82 / 18$ & $73 / 27$ \\
\hline $\mathbf{2}$ & Белгородская область & $57 / 43$ & $56 / 44$ & $79 / 21$ & $66 / 34$ \\
\hline $\mathbf{3}$ & Республика Алтай & $71 / 29$ & $42 / 58$ & $76 / 24$ & $66 / 34$ \\
\hline $\mathbf{4}$ & Алтайский край & $61 / 39$ & $57 / 43$ & $75 / 25$ & $65 / 35$ \\
\hline $\mathbf{5}$ & Москва & $29 / 71$ & $65 / 35$ & $83 / 17$ & $65 / 35$ \\
\hline 6 & Магаданская область & $68 / 32$ & $36 / 64$ & $76 / 24$ & $64 / 36$ \\
\hline 7 & Курская область & $60 / 40$ & $44 / 56$ & $76 / 24$ & $63 / 37$ \\
\hline 8 & Санкт-Петербург & $41 / 59$ & $57 / 43$ & $79 / 21$ & $63 / 37$ \\
\hline 9 & Мурманская область & $53 / 47$ & $54 / 46$ & $74 / 26$ & $63 / 37$ \\
\hline 10 & Республика Коми & $63 / 37$ & $54 / 46$ & $69 / 31$ & $63 / 37$ \\
\hline
\end{tabular}


Таблица 2. Регионы России - антилидеры национального экологического рейтинга [10]

\begin{tabular}{|c|c|c|c|c|c|}
\hline № & Регион РФ & $\begin{array}{c}\text { Природо- } \\
\text { охранный } \\
\text { индекс }\end{array}$ & $\begin{array}{c}\text { Промышленно- } \\
\text { экологический } \\
\text { индекс }\end{array}$ & $\begin{array}{c}\text { Социально- } \\
\text { экологический } \\
\text { индекс }\end{array}$ & $\begin{array}{c}\text { Сводный } \\
\text { экогический } \\
\text { индекс }\end{array}$ \\
\hline 76 & Московская область & $31 / 69$ & $31 / 69$ & $73 / 27$ & $46 / 54$ \\
\hline 77 & Нижегородская область & $29 / 71$ & $40 / 60$ & $63 / 37$ & $46 / 54$ \\
\hline 78 & Оренбургская область & $28 / 72$ & $36 / 64$ & $67 / 33$ & $45 / 55$ \\
\hline 79 & Омская область & $38 / 62$ & $41 / 59$ & $55 / 45$ & $45 / 55$ \\
\hline 80 & Красноярский край & $35 / 65$ & $39 / 61$ & $59 / 41$ & $45 / 55$ \\
\hline 81 & Забайкальский край & $44 / 56$ & $32 / 68$ & $54 / 46$ & $45 / 55$ \\
\hline 82 & Республика Саха (Якутия) & $46 / 54$ & $37 / 63$ & $48 / 52$ & $45 / 55$ \\
\hline 83 & Свердловская область & $33 / 67$ & $40 / 60$ & $54 / 46$ & $43 / 57$ \\
\hline 84 & Челябинская область & $22 / 78$ & $42 / 58$ & $60 / 40$ & $42 / 58$ \\
\hline 85 & Иркутская область & $26 / 74$ & $42 / 58$ & $54 / 46$ & $42 / 58$ \\
\hline
\end{tabular}

Акцент на природоохранных действиях, защите интересов социума, работе промышленности с минимальными воздействиями на окружающую среду во многом являются результатом управленческих усилий и правильного выстраивания работы с функционирующими промышленными предприятиями в регионах.

Действия властей и промышленности ряда регионов страны, в особенности, входящих в количество лидеров по экологическому индексу, вызывают уважение, однако, следует понимать, что экологические мероприятия и социально направленные проекты требуют значительных финансовых ресурсов и одним административным способом добиться долгосрочных положительных результатов в настоящее время практически не возможно.

Характеризуя факторы устойчивого развития для региона, следует, исходя из классического восприятия данного вопроса, отобразить их следующим образом (рисунок 1).

Приведенный подход, в целом, демонстрирует в нацеленности на устойчивое развитие региона приверженность декларируемым на глобальным уровне целям устойчивого развития социума, поскольку предполагает сбалансированность социально-экономических показателей территории, рост благосостояния местного населения, оздоровление экологического состояния.

Однако, как уже упоминалось, социально ориентированные, экологические мероприятия, социально-инфраструктурные решения и, в том числе, маркетинговое сопровождение бренда региона предполагают, кроме административного ресурса, надлежащее финансирование. Зарубежный опыт в данной сфере свидетельствует о широком привлечении бизнеса к участию в таких активностях. В частности, компании по всему миру финансируют социальные и экологические инициативы и демонстрируют свою отчетность, касающуюся нацеленности на устойчивое развитие [11].

\section{Заключение}

Резюмируя, отметим, что философия устойчивого развития зарекомендовала себя в качестве варианта практического решения развития общества в практически по всему миру. Опыт развитых стран демонстрирует активный переход от «коричневой» модели экономического развития общества к «зеленой», в рамках которой приоритет отдается экономической и экологической составляющим, а экономический эффект является значимым, но вторичным. Проявившаяся за рубежом практика демонстрирует активное вовлечение бизнеса к софинансированию социальных и экологических инициатив в развитии территорий.

Можно отметить, что в России ситуация развивается в рамках общемировых трендов и регионы демонстрируют вовлеченность в решение экологических и социальных проблем. Вместе с тем, для осуществления эффективной социально-экономической региональной политики, включающей в себя достижение целей устойчивого развития, необходимо привлекать бизнес к решению стоящих проблем.

Эффективным такое вовлечение может и должно стать за счет, помимо административного ресурса, формирования общественной до- 


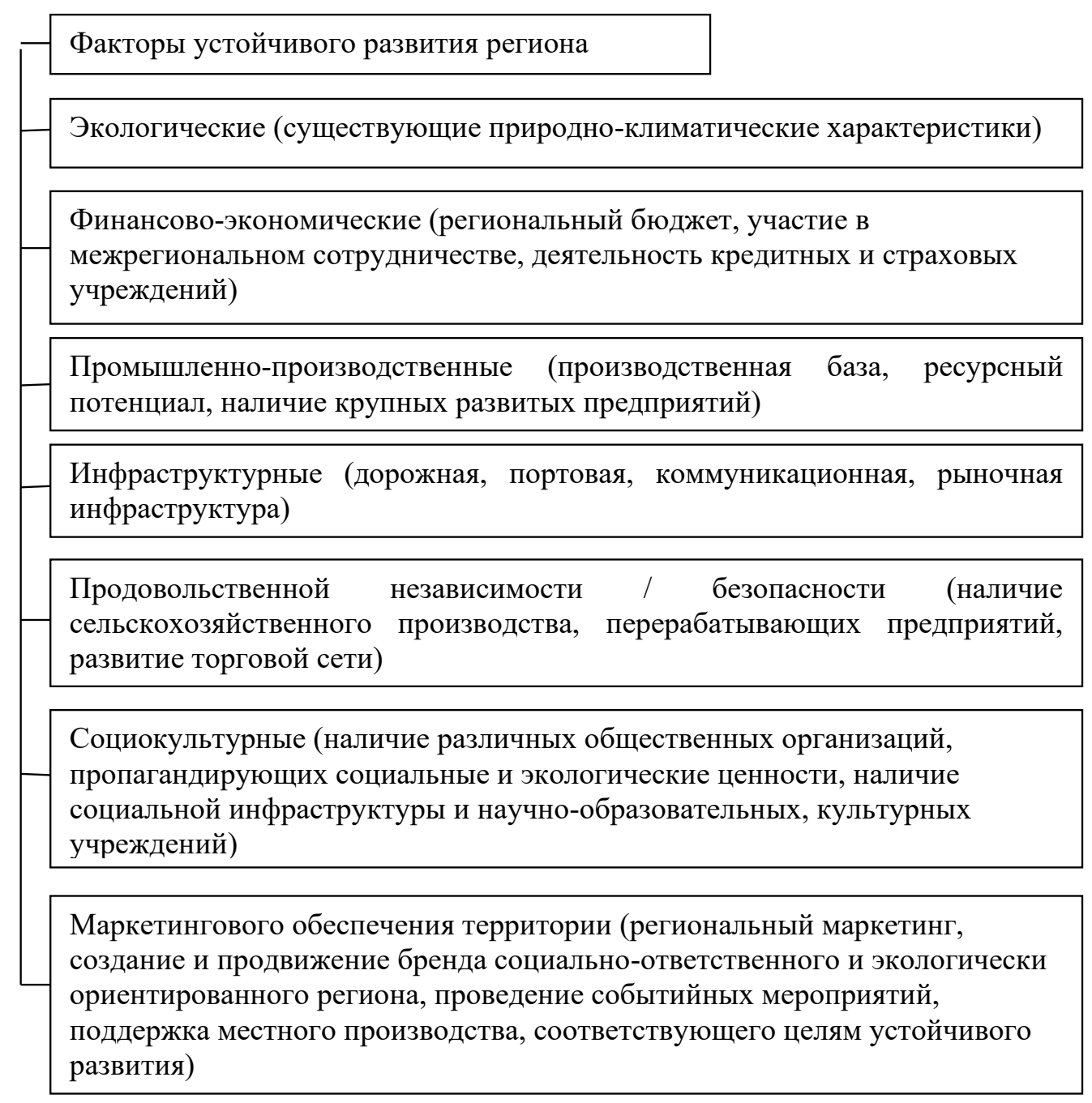

Рисунок 1. Основные факторы устойчивого развития для региона [9]

минанты повсеместного проявления этического императива со стороны социума на выбор тех предприятий и организаций, которые участвуют в решении общественных проблем. В этом случае, бизнес будет оценивать свое участие в софинансирование подобных проектов, как ценный ресурс, позволяющий повысить собственную конкурентоспособность, а далее при пролонгировании такой деловой практики, это станет нормой корпоративной культуры и делового этикета в России, способствуя осуществлению сбалансированной социально-экономической политики в регионах.

\section{Библиографический список}

1. Бондаренко В.А., Ефременко И. Н., Гузенко Н.В. Вопросы теоретического обоснования становления зеленой экономики и ее перспективы для России // Финансовые исследования. 2019. № 2 (63).С. $23-31$.

2. Иванов П. М. Алгебраическое моделирование сложных систем. М.: Наука, 1996. 185 с.

3. Лясковская Е.А. Формирование зеленой экономики и устойчивость развития страны и регионов / Е.А.Лясковская, К.А. Григорьева // Вестник ЮУргУ. Серия «Экономика и менеджмент»._ 2018.- Т. 12.- № 1.- С. 15-22.

4. Лясковская E. А. Проблемы подготовки качественных трудовых ресурсов при реализации концепции устойчивого и инновационного развития // Вестник Башкирского государственного аграрного университета.2017. - № 4 (44). - С. 137-145. 
5. Медведев дал указания проработать переход РФ на модель экологически устойчивого развития // ТАСС. 10.02.2017. URL: http://tass.ru/ekonomika/4014558 (дата обращения: 21.03.2020).

6. Навстречу зеленой экономике: пути к устойчивому развитию и искоренению бедности: обобщающий доклад для представителей властных структур [Электронный ресурс] // ЮНЕП. - 2011. - Режим доступа: http://www.unep.org/greeneconomy (дата обращения: 20.03.2020).

7. Ответственная деловая практика в зеркале отчетности: настоящее и будущее. Аналитический обзор корпоративных нефинансовых отчётов. 2015-2016 годы выпуска / Российский союз промышленников и предпринимателей. М., 2017. C. 4. URL: http://media.rspp.ru/document/1/7/4/743222fc4c6650093518c635d0e8ecdd. pdf (дата обращения: 20.03.2020).

8. Пахомова Н.В., Рихтер К.К., Малышков Г.Б. Инклюзивный устойчивый рост: приоритеты, индикаторы. Международный опыт, потенциал согласования с моделью реиндустриализации // Проблемы современной экономики. - 2014. - № 3 (51).- С. 15-24.

9. Подпругин М. О. Устойчивое развитие региона: понятие, основные подходы и факторы // Российское предпринимательство. 2012. № 24(222). С. 214-221.

10. Составлен национальный экологический рейтинг субъектов Российской Федерации. Электронный ресурс. Режим доступа: URL: https://greenpatrol.ru/ru/novosti/nacionalnyy-ekologicheskiy-reyting-subektovrossiyskoy-federacii-po-itogam-oseni-2019-goda (дата обращения: 10.04.2020)

11. Судас Л.Г. Бизнес за устойчивое развитие // Государственное управление. Электронный вестник. 2017. Выпуск № 64. С. 241-258.

12. Ускова Т.В. Устойчивое развитие региона: от концептуальных основ - к практическим результатам. /Т.В. Ускова, С. С. Копасова. // Экономические и социальные перемены в регионе: факты, тенденции, прогноз / ВНКЦ ЦЭМИ РАН. 2008. ВЫП. 43. С. 21-31.

13. Moody's: Sustainable Investing an Opportunity for Asset Managers to Generate Value and Sustain Active Management Fees // Moody's [Site]. 06.10.2016. URL: https://www.moodys.com/research/Moodys-Sustainableinvesting-an-opportunity-for-asset-managers-to-generate - PR_356142 (accessed: 20.03.2020).

14. Sustainability and Reporting Trends in 2025: Preparing for the Future / Global Reporting Initiative. May 2015. URL: https://www.globalreporting.org/resourcelibrary/Sustainability-and-Reporting-Trends-in-2025-1.pdf (accessed: 20.03.2020).

15. The UN Global Compact - Accenture Strategy CEO Study. Agenda 2030: A Window of Opportunity. The Path to 2030 // Accenture.com [Site]. URL: https://www.accenture.com/us-en/insight-un-global-compact-ceo-study (accessed: 20.03.2020). 